\title{
Pengetahuan Kesehatan Reproduksi Remaja Pelajar SLTP di Kecamatan Monta Kabupaten Bima Nusa Tenggara Barat 2016
}

\author{
Suherman ${ }^{1}$ Baharudin Anwar Siregar ${ }^{2}$ \\ 1,2Perkumpulan Promotor dan Pendidikan Kesehatan Masyrakat Indonesia (PPPKMI)
}

\begin{abstract}
Abstrak
Hasil proyeksi penduduk yang dilakukan oleh Badan Pusat Statistik (BPS) dan Bappenas tahun 2000-2025 menunjukkan bahwa struktur penduduk Indonesia didominasi oleh penduduk usia muda. Indeks Pembangunan Kesehatan Masyarakat (IPKM) Provinsi NTB menunjukkan, dari 10 kabupaten/kota di Provinsi NTB, 6 di antaranya termasuk daerah bermasalah kesehatan. Penelitian ini bertujuan untuk melihat tingkat pengetahuan Kesehatan Reproduksi Remaja (KRR) pelajar SLTP di Kecamatan Monta Kabupaten Bima Nusa Tenggara Barat. Penelitian ini menggunakan design penelitian kuasi eksperimental. Populasi dalam penelitian ini adalah pelajar SLTP di Kecamatan Monta Kabupaten Bima. Sampel penelitian berasal dari pelajar 6 SLTP berjumlah 170 Responden. Hasil penelitian menunjukan bahwa pengetahuan Kesehatan Reproduksi Remaja pelajar sebelum intervensi tidak ada yang masuk kategori baik dan 88,9\% masuk kategori kurang, sisanya berpengetahuan sedang. Setelah diintervensi, pengetahuan pelajar menjadi $7 \%$ baik, $62 \%$ kurang, sisanya masuk kategori berpengetahuan sedang. Kesimpulan perubahan pengetahuan sebelum dan sesudah intervensi yaitu ada perbedaan yang signifikan (P-Value 0,001). Diharapkan agar sekolah menambahkan materi tentang KRR Termasuk NAPZA, IMS, HIV, dan pubertas dalam kurikulum intrakulikuler maupun ekstrakurikuler. Kerja sama dengan puskesmas, BKKBN, dan BNN setempat di wilayah SLTP untuk kegiatan-kegiatan yang berkaitan dengan kesehatan reproduksi sangat perlu dilakukan secara periodik.
\end{abstract}

Kata Kunci: Kesehatan Reproduksi Remaja, SLTP, Pengetahuan

\section{Adolescents' Reproductive Health Knowledge among Junior High School Students in Sub- District Monta District Bima, West Nusa Tenggara 2016 \\ Abstract}

The projection of Indonesian population according to Central Statistics Beuro and Bappenas in the year of 2000-2025 shows that the young adult will dominate. Public Health Development Index (IPKM) of West Nusa Tenggara (Nusa Tenggara Barat-NTB) showed, 6 out of 10 districts/cities in the province have health problems. This study aims to find the level of knowledge about Adolescent Reproductive Health (ARH) among junior high school students in the Sub-District Monta, West Nusa Tenggara. The research method was quasi-experimental research design. The population in this study is the students of junior high school in the Sub-District Monta. The samples included 170 respondents from 6 junior high. The results of the study reveal that Adolescent Reproductive Health knowledge of the students before the intervention was $88.9 \%$ in the category of lack of knowledge and none of the respondents had good knowledge. After the intervention, $7 \%$ of the respondents had good knowledge and $62 \%$ had lack of knowledge. Conclusion of the study was there are significant changes in knowledge before and after the intervention (P-Value 0.001). It is recommended that the schools adds ARH topics to be disscussed (including material about drugs, STIs, HIV, and puberty) in the curriculum and extracurricular. Cooperation with primary health centers (puskesmas), $\mathrm{BKKBN}$, and local BNN with the schools for activities related to reproductive health is necessary to be arrange and done periodically.

Keywords: Adolescent Reproductive Health, junior high school, knowledge

Korespondensi: Suherman, Perkumpulan Promotor dan Pendidikan Kesehatan Masyrakat Indonesia (PPPKMI), Gedung Depkes Lantai 6 Blok C J1. HR Rasuna Said Kuningan Jakarta Selatan, mobile 08131887666385, Email: suheriau@yahoo.com

Suherman dan Siregar, Pengetahuan Kesehatan Reproduksi Remaja Pelajar SLTP 


\section{Pendahuluan}

Sebagai bagian dari kelompok remaja, perkembangan organ seksual siswa Sekolah Lanjutan Pertama (SLP) masih terus berkembang dan dampak pubertas masih akan dirasakan. Permasalahan kesehatan reproduksi dan seksual yang sering terjadi di kalangan remaja adalah perilaku seks di luar nikah dengan dampak seperti kehamilan tidak diinginkan, penularan infeksi menular seksual, serta aborsi. Pengetahuan sebagai akar perilaku kesehatan reproduksi mereka masih kurang. Kurang dari 30\% remaja laki-laki dan tidak lebih dari $20 \%$ remaja perempuan mengidentifikasi mimpi basah sebagai salah satu indokator pubertas. Demikian juga sebaliknya, sekitar $30 \%$ remaja laki-laki dan $75 \%$ remaja perempuan mengetahui bahwa menstruasi merupakan tanda pubertas pada perempuan. ${ }^{1}$

Hasil SDKI 2012 KRR menunjukkan bahwa pengetahuan remaja tentang kesehatan reproduksi belum memadai yang dilihat dengan hanya $35,5 \%$ remaja perempuan dan $31,2 \%$ remaja laki-laki usia 15-19 tahun mengetahui bahwa perempuan dapat hamil dengan satu kali berhubungan seksual. ${ }^{2}$

Jumlah remaja di Indonesia sekitar 18\% dari penduduk Indonesia dan merupakan kelompok yang sangat potensial dan memegang peran penting untuk meningkatkan status kesehatan. ${ }^{3}$ Namun demikian Indonesia termasuk negara dengan pernikahan usia muda peringkat 37 dunia, tertinggi kedua di ASEAN. Sebanyak $0.2 \%$ atau lebih dari 22.000 perempuan usia 10-14 tahun telah menikah. ${ }^{4}$ Intervensi sangat diperlukan untuk mengupayakan perubahan perilaku remaja agar saat mereka beranjak dewasa dapat menjalani proses reproduksi (menikah, hamil, melahirkan, dan menyusui) dengan baik dan melahirkan generasi yang baik juga status kesehatannya.

Situasi ini terjadi di banyak tempat di Indonesia, tidak terkecuali Kabupaten Bima, Nusa Tenggara Barat. Indeks Pembangunan Kesehatan Masyarakat (IPKM) Provinsi NTB menunjukkan, dari 10 kabupaten/kota di Provinsi NTB, 6 diantaranya termasuk daerah bermasalah kesehatan. Padahal, pelayanan kesehatan cukup bagus, sarana dan prasarana serta SDM cukup memadai, dan dukungan dari gubernur terhadap programprogram kesehatan juga baik. NTB juga termasuk satu dari kelompok penyumbang $25 \%$ kematian ibu. ${ }^{5}$ Diperlukan intervensi akar masalah agar kesehatan ibu meningkat, misalnya dengan melakukan intervensi (kesehatan reproduksi) kepada remaja.

Penelitian ini secara khusus ditujukan untuk mengetahui gambaran pengetahuan dan perilaku KRR anak didik di SLTP di Kecamatan Monta, Kabupaten Bima Nusa Tenggara Barat. Informasi mengenai 
pengetahuan dan perilaku KRR yang dihasilkan dalam penelitian ini sangat penting untuk merancang intervensi peningkatan pengetahuan dan perubahan perilaku KRR.

\section{Metode}

Penelitian ini dilakukan pada bulan Maret-April 2016 di SLTP Kecamatan Monta Kabupaten Bima Nusa Tenggara Barat. Menggunakan design penelitian Kuasi Eksperimental. Eksperimental Kuasi banyak digunakan dalam penelitian pendidikan dengan desain One group Pretest dan posttest design, dikenal juga sebagai "sebelum dan sesudah". 6

Populasi pada penelitian ini terdiri dari 6 sekolah di Kecamatan Monta yaitu MTs Nurul Muslimin, SMPN 1, SMPN 2, SMPN 3, SMPN 4, dan SMPN 6 dengan teknik pengambilan sampel purposive sampling didapat jumlah sampel 170 siswa. Pengumpulan data menggunakan tenaga bantuan, peneliti memberikan penjelasan terlebih dahulu kepada tenaga bantuan tersebut sehingga memiliki persepsi yang sama. Alat ukur yang digunakan adalah kuesioner. Analisis data dilakukan dengan analisis data univariat dan bivariat.

\section{Hasil}

Pendidikan merupakan salah satu indikator yang kerap ditelaah dalam mengukur tingkat pembangunan manusia suatu daerah. Melalui pengetahuan, pendidikan berkontribusi terhadap perubahan perilaku kesehatan. Pengetahuan yang dipengaruhi oleh tingkat pendidikan merupakan salah satu faktor pencetus yang berperan dalam mempengaruhi keputusan seseorang untuk berperilaku sehat. Dalam hasil penelitian ini dijelaskan asal sekolah responden dan tingkat pengetahuan responden mengenai kesehatan reproduksi, HIV, NAPZA dan IMS sebelum dan sesudah diberikan penyuluhan kesehatan.

Tabel 1. Distribusi Frekuensi Asal Sekolah pada Siswa Tingkat SLTP

\begin{tabular}{lll}
\hline Asal sekolah & n & $\mathbf{( \% )}$ \\
\hline MTS Nurul Muslimin & 29 & 17,1 \\
SMPN 1 & 30 & 17,6 \\
SMPN 2 & 20 & 11,8 \\
SMPN 3 & 29 & 17,1 \\
SMPN 4 & 32 & 18,8 \\
SMPN 6 & 30 & 17,6 \\
\hline Total & $\mathbf{1 7 0}$ & $\mathbf{1 0 0}$ \\
\hline
\end{tabular}

Berdasarkan hasil penelitian pada Tabel 1 dari 170 responden yang dijadikan sampel, diketahui gambaran siswa yang berasal dari SMPN 4 memilik jumlah yang paling besar dengan persentase $18,8 \%$ (32 orang) dan yang paling sedikit SMPN 2 dengan persentase 11,8 $\%$ (20 orang). 
Tabel 2. Rekapitulasi Jawaban Pre Test dan Post Test

\begin{tabular}{|c|c|c|c|c|c|c|c|c|c|}
\hline \multirow{2}{*}{ No } & \multirow{2}{*}{ Pertanyaan } & \multicolumn{2}{|c|}{ Pre Test } & \multicolumn{6}{|c|}{ Post Test } \\
\hline & & $\mathbf{B}$ & $\%$ & $\mathbf{S}$ & $\%$ & $\mathbf{B}$ & $\%$ & $\mathbf{S}$ & $\%$ \\
\hline 1. & $\begin{array}{l}\text { Lebih dari separuh pengguna NAPZA di Indonesia } \\
\text { merupakan remaja }\end{array}$ & 16 & 9.4 & 154 & 90.6 & 4 & 2.4 & 166 & 97.6 \\
\hline 2. & Satu dari tiga anak di Indonesia perokok & 28 & 16.5 & 142 & 83.5 & 22 & 12.9 & 148 & 87.1 \\
\hline 3. & Rokok tidak menimbulkan ketergantungan & 85 & 50.0 & 85 & 50.0 & 82 & 48.2 & 88 & 51.8 \\
\hline 4. & $\begin{array}{l}\text { Obat berbahaya ( Tramadol) termasuk kelompok } \\
\text { NAPAZA }\end{array}$ & 110 & 64.7 & 60 & 35.3 & 137 & 80.6 & 33 & 19.4 \\
\hline 5. & Orang bisa dengan mudah berhenti merokok & 102 & 60.0 & 68 & 40.0 & 105 & 61.8 & 65 & 38.2 \\
\hline 6. & $\begin{array}{l}\text { Berhubungan dengan seks sekali saja tidak bisa } \\
\text { mengakibatkan kehamilan }\end{array}$ & 44 & 25.9 & 126 & 74.1 & 65 & 38.2 & 105 & 61.8 \\
\hline 7. & $\begin{array}{l}\text { Berhubungan dengan seks sekali } \\
\text { mengaja }\end{array}$ & 59 & 34.7 & 111 & 65.3 & 108 & 63.5 & 62 & 36.5 \\
\hline 8. & $\begin{array}{l}\text { Hubungan Seks pertama kali bisa mengakibatkan } \\
\text { hormone pertumbuhan berhenti bekerja }\end{array}$ & 36 & 21.2 & 134 & 78.8 & 85 & 50.0 & 85 & 50.0 \\
\hline 9. & Tanda primer pubertas pada laki-laki mimpi basah & 134 & 78.8 & 36 & 21.2 & 138 & 81.2 & 32 & 18.8 \\
\hline 10. & $\begin{array}{l}\text { Tanda primer pubertas pada perempuan tertarik pada } \\
\text { lawan jenis }\end{array}$ & 50 & 29.4 & 120 & 70.6 & 36 & 21.2 & 134 & 78.8 \\
\hline 11. & Bersalaman dengan orang HIV + & 69 & 40.6 & 101 & 59.4 & 97 & 57.1 & 73 & 42.9 \\
\hline 12. & Berpelukan dengan orang HIV + & 72 & 42.4 & 98 & 57.6 & 100 & 58.8 & 70 & 41.2 \\
\hline 13. & $\begin{array}{l}\text { Menggunakan peralatan makan yang dipakai orang } \\
\mathrm{HIV}+\end{array}$ & 52 & 30.6 & 118 & 69.4 & 78 & 45.9 & 92 & 54.1 \\
\hline 14. & Berenang dikolam bersama orang HIV + & 63 & 37.1 & 107 & 62.9 & 96 & 56.5 & 74 & 43.5 \\
\hline 15. & Berhubungan sex dengan orang HIV + & 46 & 27.1 & 124 & 72.9 & 80 & 47.1 & 90 & 52.9 \\
\hline 16. & Tinggal bersama orang HIV + & 66 & 38.8 & 104 & 61.2 & 86 & 50.6 & 84 & 49.4 \\
\hline 17. & Menerima darah yang didonorkan orang HIV + & 78 & 45.9 & 92 & 54.1 & 91 & 53.5 & 79 & 46.5 \\
\hline 18. & Menggunakan narkoba suntik bersama orang HIV + & 70 & 41.2 & 100 & 58.8 & 83 & 48.8 & 87 & 51.2 \\
\hline 19. & Bekerja atau sekolah bersama orang HIV + & 80 & 47.1 & 90 & 52.9 & 85 & 50.0 & 85 & 50.0 \\
\hline & $\begin{array}{l}\text { Bayi yang dilahirkan ibu } \mathrm{HIV}+(\text { melalui plasenta } \\
\text { ASI) }\end{array}$ & 77 & 45.3 & 93 & 54.7 & 85 & 50.0 & 85 & 50.0 \\
\hline & $\begin{array}{l}\text { Berada dekat orang HIV + yang sedang batuk } \\
\text { /bersin }\end{array}$ & 43 & 25.3 & 127 & 74.7 & 69 & 40.6 & 101 & 59.4 \\
\hline 22. & Terkena tinja/urin orang HIV + & 67 & 39.4 & 103 & 60.6 & 66 & 38.8 & 104 & 61.2 \\
\hline 23. & Terkena air liur, keringat, air mata orang HIV + & 57 & 33.5 & 113 & 66.5 & 81 & 47.6 & 89 & 52.4 \\
\hline 24. & Mendonorkan darah kepada orang HIV + & 75 & 44.1 & 95 & 55.9 & 69 & 40.6 & 101 & 59.4 \\
\hline 25. & Digigit serangga (nyamuk) & 43 & 25.3 & 127 & 74.7 & 62 & 36.5 & 108 & 63.5 \\
\hline
\end{tabular}

Berdasarkan Tabel 2 diatas dapat dilihat bahwa dari 25 pertanyaan. Untuk pre test terdapat satu pertanyaan yang jawaban benar > $70 \%$, yaitu pertanyaan nomor $9(78,8 \%)$ dan terdapat dua pertanyaan yang jawabannya salah > 80\%, yaitu pertanyaan nomor 1 $(90,6 \%)$ dan soal nomor $2(83,5 \%)$. Untuk post test terdapat dua pertanyaan yang jawaban benar $>80 \%$, yaitu pertanyaan nomor
$4(80,6 \%)$ dan $9(81,2 \%)$ dan terdapat dua pertanyaan yang jawabannya salah > $80 \%$, yaitu pertanyaan nomor $1(97,6 \%)$ dan nomor $2(87,1 \%)$.

Pada Tabel 2 dapat dilihat juga bahwa dari 170 responden diketahui jumlah jawaban benar responden setelah diberikan intervensi rata-rata mengalami peningkatan, tetapi masih terdapat beberapa jawaban benar yang 
mengalami penurunan setelah diberikan intervensi yaitu pertanyaan nomor 1 (Menurun 7,0\%), 2 (Menurun 3,6\%), 3 (Menurun 9,8\%), 10 (Menurun 8,2\%), 22 (Menurun 0,6\%), dan 24 (Menurun 40,6\%).

Tabel 3. Pengetahuan Sebelum dan Sesudah diberikan Intervensi

\begin{tabular}{lllll}
\hline \multirow{2}{*}{ Pengetahuan } & \multicolumn{2}{l}{ Pre-test } & \multicolumn{2}{l}{ Post-test } \\
\cline { 2 - 5 } & $\mathbf{N}$ & $\%$ & N & $\%$ \\
\hline Kurang & 152 & 88,9 & 106 & 62,0 \\
Sedang & 18 & 10,5 & 52 & 30,4 \\
Baik & 0 & 0,0 & 12 & 7,0 \\
\hline
\end{tabular}

Berdasarkan Tabel 3 dapat dijelaskan bahwa dari 170 responden diketahui jumlah responden yang berpengetahuan kurang setelah diberikan intervensi turun sebesar 26,9 $\%$ (46 orang) dan pengetahuan sedang meningkat sebanyak 19,9 (34 orang) sedangkan responden yang berpengetahuan baik yang pada awalnya berjumlah $0 \%$ meningkat sebesar 7,0\% (12 orang), dapat disimpulkan rata-rata pengetahuan responden meningkat setelah diberikan intervensi.

Tabel 4. Distribusi Rata-Rata Pengetahuan Siswa SLTP Sebelum dan Sesudah diberikan Penyuluhan

\begin{tabular}{llllll}
\hline Variabel & Mean & St. Deviasi & St. Error & P-Value & N \\
\cline { 1 - 4 } Tingkat Pengetahuan & & & & & \\
\hline Sebelum & 1,11 & 0,309 & 0,24 & 0,001 & \multirow{2}{*}{170} \\
\hline Sesudah & 1,45 & 0,625 & 0,48 & & \\
\hline
\end{tabular}

Rata-rata pengetahuan siswa SLTP sebelum diberikan Penyuluhan adalah sebesar 1,11 dengan standar deviasi 0,309, sedangkan rata-rata pengetahuan siswa SLTP sesudah diberikan penyuluhan sebesar 1,45 dengan Standar deviasi 0,625. Nilai P-Value sebesar 0,001 maka dapat disimpulkan bahwa ada perbedaan pengetahuan siswa SMP sebelum dan sesudah diberikan penyuluhan.

\section{Pembahasan}

Skor pengetahuan Kesehatan Reproduksi Remaja tentang HIV, NAPZA, IMS sebelum dan sesudah intervensi menerangkan ada perbedaan yang signifikan antara tingkat pengetahuan remaja sebelum dan sesudah intervensi, yaitu rata-rata pengetahuan siswa SLTP Sebelum diberikan Penyuluhan adalah Sebesar 1,11 dengan Standar deviasi 0,309 Sedangkan rata-rata pengetahuan siswa SLTP sesudah diberikan penyuluhan sebesar 1,45 dengan Standar deviasi 0,625. Nilai P-Value sebesar 0,001 maka dapat disimpulkan bahwa ada perbedaan pengetahuan siswa SMP sebelum dan sesudah diberikan penyuluhan.

Hasil penelitian ini sesuai dengan data SDKI 2012 yang menemukan bahwa pengetahuan HIV-AIDS masih rendah yakni 77 persen wanita umur 15-49 tahun dan 82 persen pria kawin umur 15-54 tahun pernah mendengar HIV-AIDS. Kecamatan monta merupakan daerah perdesaan yang 
masyarakatnya masih jarang terpapar informasi mengenai kesehatan terutama HIV/ AIDS hal ini sejalan dengan data SDKI 2012 yang menemukan bahwa masyarakat yang bertempat tinggal di perkotaan lebih banyak mendengar tentang AIDS dibandingkan dengan mereka yang tinggal di perdesaan. Selain itu rendahnya pengetahuan mengenai kesehatan khususnya HIV/AIDS bisa disebabkan karena Kabupaten Bima angka melek hurufnya masih tinggi yaitu, 79,19\%, dengan persentase Angka Melek Huruf $(\mathrm{AMH})$ tertinggi terdapat di Kecamatan Sanggar (86,07\%), sedangkan terendah ada dikecamatan Monta $(73,81 \%){ }^{2}$

Penelitian ini sejalan dengan penelitian yang dilakukan oleh Irma (2015) yang menunjukkan ada perbedaan yang signifikan antara tingkat pengetahuan kesehatan reproduksi remaja dengan sebelum dan sesudah diberikan intervensi dengan rata-rata 27,23 dan sesudah diberikan intervensi 32,06. ${ }^{7}$ Penelitian serupa juga dilakukan oleh Asih (2014) hasil penelitian menunjukkan terjadi peningkatan responden yang berpengetahuan baik dari 4 responden $(13,3 \%)$ menjadi 8 responden $(26,7 \%)$ setelah diberikan pendidikan kesehatan reproduksi. ${ }^{8}$

Penelitian ini merupakan penelitian yang menggunakan pendekatan desain cross sectional dimana variabel independen dan variabel dependen diteliti dalam waktu yang bersamaan, sehingga rancangan ini hanya dapat menggambarkan kekuatan hubungan antara variabel independen dengan variabel dependen tetapi tidak menggambarkan hubungan sebab akibat. Selain itu, instrumen yang digunakan dalam pengumpulan data adalah kuesioner yang diisi sendiri oleh responden sehingga kemungkinan responden ada yang tidak jujur dalam menjawab pertanyaan.

\section{Simpulan}

Pendidikan kesehatan reproduksi melalui penyuluhan dapat mempengaruhi atau meningkatkan pengetahuan kesehatan reproduksi, HIV, NAPZA, dan IMS pada siswa SLTP Kecamatan Monta. Sekolah diharapkan mempunyai sarana informasi mengenai kesehatan reproduksi remaja baik pembuatan majalah untuk memberikan informasi kepada siswa tentang kesehatan reproduksi remaja termasuk NAPZA, IMS, HIV, dan masa pubertas. Sekolah dapat memasukan materi tentang Kesehatan Reproduksi Remaja Termasuk NAPZA, IMS, HIV, masa pubertas kedalam kurikulum intrakulikuler maupun ekstrakulikuler. Kerjasama dengan puskesmas daerah diwilayah SLTP terdekat untuk kegiatankegiatan yang berkaitan dengan kesehatan reproduksi khususnya NAPZA, IMS, HIV, masa pubertas.

\section{Daftar Pustaka}

1. Badan Pusat Statistik (BPS) (2007). Survey Kesehatan Reproduksi Remaja Indonesia. Jakarta.

2. Badan Pusat Statistik (BPS), Badan Koordinasi Keluarga Berencana Nasional (BKKBN), Kementrian Kesehatan, dan Macro Internasional. 2013. Survei Demografi dan Kesehatan Indonesia 2012. Calverton, USA: BPS and ICF 
Internasional.

3. Badan Pusat Statistik (BPS) (2010).

Sensus Penduduk 2010. Jakarta.

4. Badan Koordinasi Keluarga Berencana Nasional (BKKBN) (2012). Kajian Pernikahan Dini pada Beberapa Provinsi di Indonesia Dampak Overpopulation, Akar Masalah dan Peran Kelembagaan di Daerah. Jakarta.

5. Kemenkes, (2012) Supervisi Terpadu ke Provinsi Nusa Tenggara Barat. http://www.depkes.go.id/index.php/berita/ press-release/1927-supervisi-terpadu-keprovinsi-nusa-tenggara-barat.html.

Diunduh 6 Maret 2013.

6. Sastroasmoro, Sudigdo, dkk. (2002). Dasar-Dasar Metodologi Penelitian Klinis Edisi Ke -2. CV Segung Seto: Jakarta.

7. Irma Samrotunnajah (2015). Peningkatan Pengetahuan HIV dan AIDS Remaja Dengan Metode Diskusi Pada siswa SMAN 11 Kota Tangerang Selatan Tahun 2015, Skripsi. Jakarta. FKK UMJ.

8. Arosna, Asih Dwi, Arif Widodo, Kartinah (2014) Pengaruh Pendidikan Kesehatan Reproduksi Terhadap Pengetahuan Dan Sikap Mahasiswa Di FIK-UMS. Skripsi, Universitas Muhammadiyah Surakart 